\title{
Bacterial vaginosis: Prevalence and associated risk factors among non-pregnant women of reproductive age attending a Nigerian tertiary hospital
}

\author{
Rasheedat M Abdullateef ${ }^{1}$, Munirdeen A Ijaiya $^{2}$, Fadeyi Abayomi ${ }^{3}$, Abiodun \\ $S$ Adeniran ${ }^{2}$, Haruna Idris ${ }^{1}$ \\ 1.Obstetrics \& Gynaecology Department, Federal Medical Centre, Bida, Nigeria \\ 2.Obstetrics \& Gynaecology Department, University of Ilorin/ University of Ilorin Teaching Hospital, Ilorin, \\ Nigeria \\ 3.Departmet of Medical Microbiology and Parasitology, University of Ilorin/ University of Ilorin Teaching \\ Hospital, Ilorin, Nigeria
}

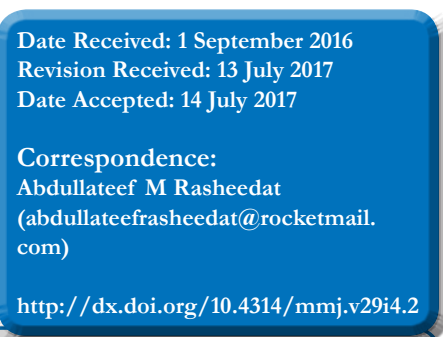

Abstract

Aim

To determine the prevalence and risk factors associated with bacterial vaginosis (BV) among non-pregnant women of reproductive age group.

Methods

A cross-sectional study among non-pregnant asymptomatic women aged 19 to 45 years, attending the gynaecological clinic at University of Ilorin Teaching Hospital, Ilorin, Nigeria. Participants were counselled and an informed consent was obtained. This was followed by vaginal swabs for microscopy, culture and sensitivity. Diagnosis of BV was by Nugent's criteria. Data analysis was by Statistical Package for Social Sciences (SPSS) version 20.0. Chi-square and Yates corrected chi-square were calculated, and p value $<0.05$ was significant.

Results

Among the 212 participants, prevalence of BV was 40.1\%; it was common among women aged 25-34 years (50; 58.8\%), the married $(77 ; 90.6 \%)$ and those with tertiary education $(39 ; 45.9 \%)$. The risk factors for BV were common among women with laboratory evidence of the infection, however statistically significant risk factors were the use of intrauterine device (OR $1.61,95 \%$ CI 0.543 4.759; $\mathrm{p} 0.020$ ) and previous voluntary termination of pregnancy (OR 1.04, 95\%CI 0.600-1.808; p0.047).

Conclusion

There was high prevalence of bacterial vaginosis in the study population. Universal screening and treatment of cases may assist in lowering the associated morbidity.

\section{Introduction}

Bacterial vaginosis (BV), formerly called non-specific vaginitis, is a polymicrobial disease characterized by reduction in lactobacilli and hydrogen peroxide production, a rise in vaginal $\mathrm{pH}$ and overgrowth of $\mathrm{BV}$ associated organisms ${ }^{1}$. These BV associated pathogens are Gardnerella vaginalis, Ureaplasma urealyticum and anaerobes of the genera Peptostreptococcus, Bacteroides, Mobiluncus, Prevotella, Fusobacterium, Veillonella and Eubacterium.

BV affects $10.0 \%$ of females ${ }^{2}$ and its prevalence varies from $12.0-30.0 \%{ }^{3-7}$. It is the commonest cause of abnormal vaginal discharge in women of childbearing age ${ }^{8}$ although majority of cases are asymptomatic and remain unreported ${ }^{8}$. $\mathrm{BV}$ is associated with an increased risk of pelvic inflammatory disease, postoperative infections, cervicitis, HIV infection and probably cervical intraepithelial neoplasia ${ }^{1-4}$. Premature rupture of membranes, preterm labour and delivery, chorioamnionitis and post-partum endometritis are some of the obstetric complications ${ }^{1-8}$. Diagnostic tests for BV such as Amsel's, Nugent's or Spiegel's criteria, gas-liquid chromatography with succinate:lactate ratio $>4$ and Fem Exam card test kit are available. BV has several adverse reproductive health outcomes and treatment of the condition in women of childbearing age will reduce these adverse outcomes. This study aimed at determining the prevalence and risk factors for BV among non-pregnant women of reproductive age in Ilorin, Nigeria and generate an otherwise dearth of data for this group of women.

\section{Methods}

The study was a cross-sectional study involving non-pregnant women aged 19 to 45 years attending the gynaecological clinic of the University of Ilorin Teaching Hospital, Ilorin Nigeria conducted between November, 2011 and March, 2012. Consenting eligible participants were recruited and participated in the study. Pregnancy, menstruation, abnormal vaginal bleeding, urinary or faecal incontinence and antibiotics use within 72 hours prior to presentation were the exclusion criteria.

Using previously documented prevalence of $\mathrm{BV}$ in nonpregnant women of $14.0 \% 6$ and the Fisher's formula ${ }^{9}$, the sample size of 212 participants including $10 \%$ attrition rate was calculated. The participants were selected by a systematic random sampling technique in which one out of every two patients at the clinic who satisfied the inclusion criteria was recruited until the sample size was attained. An intervieweradministered questionnaire purposely designed for the study was used to collect relevant information including sociodemography, douching, smoking, contraception, sexual history, history of previous preterm deliveries and sex with a high risk partner. A high-risk partner was defined as one who practices unprotected sex, has multiple sexual partners, has sex with a partner who has multiple other partners or has sex with intravenous drug users.

Vaginal swabs were collected by the researchers during speculum examination by passing sterile cotton wool swab into the fornix and gently rotated against the vaginal wall to obtain vaginal secretion specimens taking precaution to 
avoid collecting cervical secretion. Swab specimens were placed inside Amines's transport medium for transportation to the medical microbiology laboratory for processing.

The vaginal swab was used for microscopy by making a thin smear on clean, dry and grease-free glass slides, air dried and gram stained. The stained slide was first examined under $x 40$ then x100 objective of a compound light microscope. Three characteristic morphocytes i.e. Lactobacillus, Mobiluncus and Gardnerella, were sought during microscopic examination using their characteristics and scored appropriately using Nugent's Criteria ${ }^{10}$.

All data was entered into the database and analysed using Statistical Package for Social Sciences (SPSS) version 20.0. Results were presented in tables.Categorical variables were described by proportions and comparison of the study and control groups was done using chi-square or Yates corrected chi-square. Odds ratio and $\mathrm{p}<0.05$ were termed significant. Institutional ethical approval was obtained before commencement of the study; participants were counselled and a written informed consent obtained at recruitment.

\section{Results}

A total of 212 non-pregnant women of reproductive age participated in the study, 85 were positive for BV giving a prevalence of $40.1 \%$. It was commonest among the 25 to 34 years age range $(50 ; 58.8 \%)$. Nugent scoring showed that $33(15.6 \%)$ had a score of $1-3,94(44.3 \%)$ a score of $4-6$ while $85(40.1 \%)$ had a score of 7 or more. From table 1 , the modal age group of participants with BV was 30 to 34 years (28; $32.9 \%), 77(90.6 \%)$ were married while $39(45.9 \%)$ had tertiary education. However, there was no statistical significance in the occurrence of $\mathrm{BV}$ and the socio-demographic characteristics of the participants.

Table 1: Relationship between demographic characteristics and bacterial vaginosis

\begin{tabular}{|c|c|c|c|c|c|}
\hline \multirow[t]{3}{*}{ Variables } & \multicolumn{2}{|c|}{ Bacterial Vaginosis } & \multirow[t]{3}{*}{$\chi^{2}$} & \multirow[t]{3}{*}{ OR $(95 \% \mathrm{CI})$} & \multirow[t]{3}{*}{$\mathrm{p}$ value } \\
\hline & Present & Absent & & & \\
\hline & $\mathrm{n}=85(\%)$ & $\mathrm{n}=127(\%)$ & & & \\
\hline \multicolumn{6}{|l|}{$\begin{array}{l}\text { Age } \\
\text { group(years) }\end{array}$} \\
\hline$<20$ & $1(1.2)$ & $0(0)$ & $0.049^{\mathrm{Y}}$ & UD & 0.826 \\
\hline $20-24$ & $7(8.2)$ & $9(7.1)$ & 0.174 & $1.27(0.383-4.390)$ & 0.677 \\
\hline $25-29$ & $22(25.9)$ & $40(31.5)$ & 0.037 & $0.92(0.378-2.221)$ & 0.847 \\
\hline $30-34$ & $28(32.9)$ & $36(28.3)$ & 0.343 & $1.30(0.543-3.093)$ & 0.558 \\
\hline $35-39$ & $15(17.6)$ & $22(17.3)$ & 0.067 & $1.14(0.430-3.001)$ & 0.796 \\
\hline$\geq 40^{\mathrm{REF}}$ & $12(14.1)$ & $20(15.7)$ & & & \\
\hline \multicolumn{6}{|l|}{ Marital status } \\
\hline Single & $6(7.1)$ & $5(3.9)$ & $0.000^{Y}$ & $1.20(0.059-24.473)$ & 1.000 \\
\hline Married & $77(90.6)$ & $116(91.3)$ & $0.000^{Y}$ & $0.66(0.041-10.773)$ & 1.000 \\
\hline Separated & $1(1.2)$ & $5(3.9)$ & $0.000^{Y}$ & $\begin{array}{l}0.20(0.006- \\
6.664)\end{array}$ & 1.000 \\
\hline Widowed ${ }^{\text {REF }}$ & $1(1.2)$ & $1(0.8)$ & & & \\
\hline \multicolumn{6}{|l|}{ Education } \\
\hline None & $6(7.1)$ & $5(3.9)$ & 0.893 & $2.22(0.6352-7.726)$ & 0.345 \\
\hline Primary & $13(15.3)$ & $17(13.4)$ & 0.682 & $1.41(0.621-3.207)$ & 0.409 \\
\hline Secondary & $27(31.8)$ & $33(26.0)$ & 1.599 & $1.51(0.796-2.867)$ & 0.206 \\
\hline Tertiary REF & $39(45.9)$ & $72(56.7)$ & & & \\
\hline
\end{tabular}

$X^{2}$ : Chi square; Y: Yates corrected chi-square; UD: Undefined
Table 2: Relationship between risk factors and occurrence of Bacterial Vaginosis

\begin{tabular}{|c|c|c|c|c|c|}
\hline Variables & $\begin{array}{l}\text { Bacterial } \\
\text { Present } \\
\mathrm{n}=85(\%)\end{array}$ & $\begin{array}{l}\text { Vaginosis } \\
\text { Absent } \\
\text { n=127\%) }\end{array}$ & $x^{2}$ & OR $(95 \% \mathrm{CI})$ & $p$ value \\
\hline \multicolumn{6}{|c|}{ Coitarche (years) } \\
\hline$<18$ & $10(11.8)$ & $18(14.2)$ & 0.258 & $0.81(0.353-1.846)$ & 0.612 \\
\hline$\geq 18$ & $75(88.2)$ & $109(85.8)$ & & & \\
\hline \multicolumn{6}{|c|}{ Sexual partners } \\
\hline 0 & $1(1.2)$ & $1(0.8)$ & $0.000^{x}$ & $1.00(0.020-50.400)$ & 1.000 \\
\hline 1 & $46(54.1)$ & $79(62.2)$ & $0.126^{Y}$ & $0.58(0.036-9.533)$ & 0.723 \\
\hline 2 & $31(36.5)$ & $40(31.5)$ & $0.296^{Y}$ & $0.78(0.047-12.889)$ & 0.586 \\
\hline 3 & $6(7.1)$ & $6(4.7)$ & $0.583^{x}$ & $1.00(0.050-19.964)$ & 0.445 \\
\hline 4 & $1(1.2)$ & $1(0.8)$ & & & \\
\hline \multicolumn{6}{|c|}{ At risk partner } \\
\hline Yes & $24(28.2)$ & $30(23.6)$ & 0.336 & $1.27(0.565-2.857)$ & 0.562 \\
\hline No & $44(51.8)$ & $70(55.1)$ & 0.000 & $0.99(0.489-2.040)$ & 0.996 \\
\hline Don't know & $17(20.0)$ & $27(21.3)$ & & & \\
\hline \multicolumn{6}{|c|}{ Vaginal douching } \\
\hline Yes & $36(42.4)$ & $60(47.2)$ & 0.492 & $0.82(0.472-1.427)$ & 0.483 \\
\hline No & $49(57.6)$ & $67(52.8)$ & & & \\
\hline \multicolumn{6}{|c|}{$\begin{array}{l}\text { Douching } \\
\text { frequency(n=96) }\end{array}$} \\
\hline $1-10$ & $4(11.1)$ & $8(13.3)$ & 0.015 & $0.75(0.208-2.700)$ & 0.901 \\
\hline $11-20$ & $0(0)$ & $4(6.7)$ & $1.167^{\mathrm{Y}}$ & 0.000 (UD) & 0.280 \\
\hline$>20$ & $32(88.9)$ & $48(80.0)$ & & & \\
\hline \multicolumn{6}{|c|}{ Previous discharge } \\
\hline Yes & $45(52.9)$ & $72(56.7)$ & 0.290 & $0.86(0.495-1.492)$ & 0.590 \\
\hline No & $40(47.1)$ & $55(43.3)$ & & & \\
\hline \multicolumn{6}{|l|}{$\begin{array}{l}\text { Malodorous } \\
\text { discharge }\end{array}$} \\
\hline Yes & $16(18.8)$ & $21(16.5)$ & 0.185 & $1.17(0.571-2.399)$ & 0.667 \\
\hline No & $69(81.2)$ & $106(83.5)$ & & & \\
\hline & & & & & \\
\hline
\end{tabular}

$X^{2}$ : Chi square; Y: Yates corrected chi-square; UD: Undefined

Table 3: Relationship between family setting, contraception with previous

\begin{tabular}{|c|c|c|c|c|c|}
\hline \multirow[t]{3}{*}{ Variables } & \multicolumn{2}{|c|}{ Bacterial Vaginosis } & \multirow[t]{3}{*}{$x^{2}$} & \multirow[t]{3}{*}{ OR $(95 \% \mathrm{CI})$} & \multirow[t]{3}{*}{$p$ value } \\
\hline & Present & Absent & & & \\
\hline & n (\%) & n (\%) & & & \\
\hline \multicolumn{6}{|c|}{ Family type $(\mathrm{n}=201)$} \\
\hline Monogamous & $54(69.2)$ & $96(78.1)$ & 1.960 & $0.63(0.333-1.204)$ & 0.162 \\
\hline Polygamous & $24(30.8)$ & $27(21.9)$ & & & \\
\hline \multicolumn{6}{|l|}{ Contraception } \\
\hline Yes & $22(25.9)$ & $42(33.1)$ & 1.249 & $0.71(0.384-1.301)$ & 0.264 \\
\hline No & $63(74.1)$ & $85(66.9)$ & & & \\
\hline \multicolumn{6}{|c|}{ Type of contraception } \\
\hline IUD & $15(68.2)$ & $24(57.1)$ & 0.739 & $1.61(0.543-4.759)$ & 0.390 \\
\hline Other methods & $7(31.8)$ & $18(42.9)$ & & & \\
\hline \multicolumn{6}{|l|}{ Previous VTOP } \\
\hline Yes & $39(45.9)$ & $57(44.9)$ & 0.021 & $1.04(0.600-1.808)$ & 0.886 \\
\hline No & $46(54.1)$ & $70(55.1)$ & & & \\
\hline \multicolumn{6}{|c|}{ Number (VTOP = 96) } \\
\hline 1 & $24(61.5)$ & $33(57.9)$ & $0.000^{Y}$ & $1.46(0.125-16.981)$ & 1.000 \\
\hline 2 & $11(28.9)$ & $18(31.6)$ & $0.221^{\mathrm{Y}}$ & $\begin{array}{c}1.22 \\
(0.099-15.114) \\
\end{array}$ & 0.638 \\
\hline 3 & $3(7.9)$ & $4(7.0)$ & $0.179^{\mathrm{y}}$ & $\begin{array}{c}1.50 \\
(0.089-25.393)\end{array}$ & 0.672 \\
\hline 4 & $1(2.6)$ & $2(3.5)$ & & & \\
\hline \multicolumn{6}{|l|}{ Preterm delivery } \\
\hline Yes & $9(10.6)$ & $10(7.9)$ & 0.460 & $1.39(0.538-3.567)$ & 0.498 \\
\hline No & $76(89.4)$ & $117(92.1)$ & & & \\
\hline
\end{tabular}

Chi square; Y: Yates corrected chi-square; UD: Undefined 
IUD: Intrauterine Device, VTOP: Voluntary Termination of

Pregnancy

Table 4: Multivariate analysis of risk factors for bacterial vaginosis

\begin{tabular}{|c|c|c|c|}
\hline Variable & $\mathbf{B}$ & $p$ value & OR $(95 \% \mathrm{CI})$ \\
\hline Coitarche & -1.053 & 0.539 & $0.35(0.012-10.066)$ \\
\hline \multicolumn{4}{|l|}{ Sexual partners } \\
\hline 1 & -21.816 & 1.000 & 0.00 (UD) \\
\hline 2 & -20.875 & 1.000 & 0.00 (UD) \\
\hline 3 & -41.953 & 0.999 & 0.00 (UD) \\
\hline Malodorous vaginal & -1.621 & 0.318 & $0.20(0.008-4.759)$ \\
\hline \multicolumn{4}{|l|}{ discharge } \\
\hline Family planning type & -0.320 & 0.799 & $0.73(0.062-8.521)$ \\
\hline Number of VTOP & -0.916 & 0.368 & $0.40(0.054-2.939)$ \\
\hline Preterm delivery & 0.600 & 0.727 & $1.82(0.063-52.867)$ \\
\hline
\end{tabular}

UD: Undefined; VTOP: Voluntary Termination of Pregnancy.

From table 2, BV was associated with coitarche after 18 years $(75 ; 88.2 \%)$, primiparity $(46 ; 54.1 \%)$, douching frequency $>20(32 ; 88.9 \%)$ and previous vaginal discharge $(45 ; 52.9 \%)$. However, none of these was statistically significant.

Table 3 shows that the use of intrauterine device (IUD) (OR $1.61,95 \% \mathrm{CI} 0.543-4.759 ; \mathrm{p} 0.020)$ and previous voluntary termination of pregnancy (OR 1.04, 95\% CI 0.600-1.808; $\mathrm{p} 0.047$ ) were statistically significant risk factors in BV.

Multivariate analysis (table 4) showed that none of the risk factors for BV was statistically significant in the development of the infection.

\section{Discussion}

This study reported a high prevalence rate of $40.1 \%$ for bacterial vaginosis (BV) among asymptomatic women of reproductive age. The previously identified sociodemographic, obstetric, gynaecological and social risk factors were identified among participants with BV in this study but only the use of intrauterine contraception and previous unsafe abortion were statistically significant. This suggests that a universal approach combining both targeted and opportunistic screening of women in the reproductive age at contacts with the health care provider could be explored to prevent the associated morbidity of the infection.

The high prevalence of BV in this study compares to $20.0 \%$ to $49.0 \%$ from other African countries ${ }^{11-13}$. Although BV is reported as commoner in black compared to white women, 13 there is no clear explanation for the racial difference although we suggest that socioeconomic factors may be contributory.

Socio-demographic characteristics were not significantly associated with BV in this study similar to the report of Baisley et $\mathrm{al}^{14}$. Another study which reported higher BV among younger women with low level of formal education was not statistically significant ${ }^{15}$. However, Ness et a $1^{16}$ and Ashraf-Ganjoei ${ }^{17}$ both reported a significant association between low level of education and BV. This may be because low social class has been associated with high risky sexual behaviours that may increase acquisition of Reproductive Tract Infections (RTIs) including BV. ${ }^{16,17}$ In our study, majority of women had tertiary education. This may be because our study is hospital-based where women of higher educational level come more since they are more likely to be able to afford the cost of care. This is a possible explanation for the different reports from different studies.

There was no statistical significant association between number of life time sexual partners, marriage type and male partner high-risk behaviour relative to acquisition of BV in this study. However, some researchers reported a three-fold increase in probability for BV among women with multiple lifetime sexual partners ${ }^{18,19}$ while another stud ${ }^{20}$ reported a lower prevalence of $\mathrm{BV}$ in monogamous relationships. A probable explanation for this study report may be that participants may have been unaware of the partners' highrisk sexual behaviour or unwilling to reveal them. The high rates of $\mathrm{BV}$ have been shown to be associated with other reproductive tract infections (RTIs). A concurrence rate of $68 \%$ was reported for BV and other RTIs in a multinational study from Kenya, Rwanda and South Africa ${ }^{21}$ while a comparative study reported higher prevalence of $\mathrm{BV}$ in HIV-positive women $(46.0 \%$ vs. $20.5 \%, \mathrm{p}<0.05)$ as well as higher prevalence for women with CD4 count $<350$ cell/ $\mathrm{mm}^{3}(67 \% \text { vs. } 22 \%)^{22}$. A report from Malawi stated that the disturbance of vaginal flora by $\mathrm{BV}$ predisposes to increased HIV acquisition in pregnancy with an odd of 3.7 for antenatal and 2.3 for postnatal seroconversion ${ }^{23}$. If this association can be proved to be causal, it may explain the high prevalence of HIV infection in African countries where BV rate is correspondingly high. However, this study is limited in this regard as its design did not provide for a concurrent evaluation for other RTIs in the participants.

A statistically significant link has been established between BV and sexual contact with new and multiple partners thereby emphasizing the need for safe sex practices ${ }^{24}$. The required protection is not limited to unwanted pregnancy but also includes the risk for other RTIs. This study demonstrated higher occurrence of BV among IUD users corroborating a previous report of alteration of vagina flora in favour of the growth of $\mathrm{BV}$-associated organisms by IUD in-situ ${ }^{17}$. However, progestin-only contraceptives were associated with lower likelihood of BV in another study ${ }^{21}$. Therefore, women with higher risk for BV should consider barrier or hormonal contraceptives before IUD in order to reduce risk for infection.

Although over $45.0 \%$ of participants in this study practiced douching, it has no significant association with BV. Other researchers also reported that despite being a common risk factor, douching was not statistically significant for BV infection ${ }^{12,15}$. Another study showed that women who douched were 1.2 to 5.1 times more likely to develop BV than those who did not depending on the frequency of vaginal douching ${ }^{22}$. Nonetheless, the different reports on the association between $\mathrm{BV}$ and douching may be related to the contents or agents used for douching by different individuals which, apparently, were not investigated in these studies.

Previous history of preterm delivery was found to be associated with BV occurrence in this study corroborating a previous report ${ }^{17}$. Therefore, women with prior history of preterm births should be screened for BV in early pregnancy and those found positive should be actively treated for the infection in the early second trimester to prevent a recurrence ${ }^{17}$.

The association between the frequency of voluntary termination of pregnancy (VTOP) and higher occurrence of BV in this study corroborates a previous report which attributed this to the alteration of vaginal flora in favour of the growth of $\mathrm{BV}$ associated organisms ${ }^{18}$. This becomes important especially in countries with restrictive abortion laws where VTOP is synonymous with unsafe abortion. 


\section{Strengths and limitations of the study}

The strength of this study is that it affords previously unavailable data on BV among non-pregnant women in North-Central Nigeria contributing to the pool of available data on the infection in this group of women. The design of the study as hospital-based is a limitation as women in the community who did not present at the health facility were excluded from the study.

\section{Conclusion}

This study showed a high prevalence (40.1\%) of BV among non-pregnant asymptomatic women of reproductive age attending a gynaecological clinic at University of Ilorin Teaching Hospital, Ilorin, Nigeria. However, most of the risk factors for $\mathrm{BV}$ were not statistically significant among the participants. Therefore, the study suggests that a universal approach combining targeted and opportunistic screening may be effective in preventing the attendant morbidities of BV among women.

\section{Declaration of conflicts of interest}

The authors declare no conflict of interest in the conduct of the study.

\section{References}

1.Holzman C, Levanthal JM, Qiu H, Jones NM, Wang J, The Bacterial Vaginosis Study Group. Factors linked to Bacterial Vaginosis in Nonpregnant Women. Am J Public Health 2001;19(10): 1664-1670

2.Puri K, Madan A, Bajaj K. Incidence of various causes of vaginal discharge among sexually active females in age group 20-40 years. Indian J Derm Venereology Leprology. 2003;69(2):122-125

3.Joesoef M, Karundeng A, Runtupalit C, Moran J, Lewis J, Ryan C. High rate of bacterial vaginosis among women with intrauterine devices in Manado, Indonesia. Contraception. 2001;64(3):169-172

4.Reid G, Charbonneau D, Erb J, et al. Oral use of Lactobacillus rhamnosus GR-1 and L. fermentum RC-14 significantly alters vaginal flora: randomized, placebo-controlled trial in 64 healthy women. FEMS Immun Med Microbiol. 2003;35(2):131-134

5.de Lima-Soares V, De Mesquita AMTS, Cavalcante FGT, et al. Sexually transmitted infections in a female population in rural northeast Brazil: prevalence, morbidity and risk factors. Trop Med Int Health. 2003;8(7):595-603

6.Anukam KC, Reid G. Organisms associated with bacterial vaginosis in Nigerian women as determined by PCR-DGGE and 16S rRNA gene sequence. Afr Health Sci. 2007;7(2):68-72

7.Mania-Pramanik J, Kerkar S, Salvi V. Bacterial vaginosis: a cause of infertility? Int J STD AIDS. 2009;20(11):778-781

8.Verstraelen H, Verhelst R, Vaneechoutte M, Temmerman M. The epidemiology of bacterial vaginosis in relation to sexual behaviour. BMC Infectious Diseases. 2010;10:81 doi:10.1186/1471-2334-10-81

9.Araoye MO. Research Methodology with Statistics for Health and Social sciences. Ilorin: Nathadex Press 2003: 115-121
10.Nugent RP, Krohn MA, Hillier SL. Reliability of diagnosing bacterial vaginosis is improved by a standardized method of gram stain interpretation. J Clin Microbiol 1991;29: 297-301

11.Ayenalem S, Yusuf L, Ashenafi M. Lactic Acid Bacterial Vaginosis among Outpatients in Addis Ababa. J Health Dev. 2010;24(3):198-204

12.Demba E, Morison L, van Der Loeff M, et al. Bacterial vaginosis, vaginal flora patterns and vaginal hygiene practices in patients presenting with vaginal discharge syndrome in The Gambia, West Africa. BMC Infectious Diseases. 2005;5:12. doi:10.1186/1471-2334-5-12

13.Ness RB, Hillier S, Richter HE, et al. Can known risk factors explain racial differences in the occurrence of bacterial vaginosis? J Nat Med Ass. 2003;95(3):201-212

14.Baisley K, Changalucha J, Weiss HA, et al. Bacterial vaginosis in female facility workers in north-western Tanzania: prevalence and risk factors. Sexually Transmitted Infections. 2009;85(5):370-375

15.Achondou AE, Fumoloh FF, Aseneck AC, Awah AR, Utokoro AJ. Prevalence of bacterial vaginosis among sexually active women attending the CDC central clinic Tiko, South West Region, Cameroon. Afr J Infect Dis 2016;10(2):96-101

16.Ness RB, Hillier SL, Kip KE, et al. Bacterial vaginosis and risk of pelvic inflammatory disease. Obstet Gynecol. 2004;104(4):761-769

17.Ashraf-Ganjoei T. Risk factors for bacterial vaginosis in women attending a hospital in Kerman, Islamic Republic of Iran. East Mediterr Health J. 2005;11(3):410-415

18.Smart S, Singal A, Mindel A. Social and sexual risk factors for bacterial vaginosis. Sexually Transmitted Infections. 2004;80(1):58-62

19.Nagot N, Ouedraogo A, Defer MC, Vallo R, Mayaud P, van de Perre P. Association between bacterial vaginosis and Herpes simplex virus type-2 infection: implications for HIV acquisition studies. Sexually Transmitted Infections. 2007;83(5):365-368

20.Bradshaw CS, Morton AN, Hocking J, et al. High recurrence rates of bacterial vaginosis over the course of 12 months after oral metronidazole therapy and factors associated with recurrence. J Infect Disease. 2006;193(11):1478-1486

21.Jespers V, Crucitti T, Menten J, et al for the Vagina Biomarkers Study Group. Prevalence and correlates of bacterial vaginosis indifferent subpopulations of women in sub-Saharan Africa: A cross-sectional study. PLoS ONE 2014;9(10):e109670

22.Adelaiye SM, Shittu SO, Olayinka AT. Characterization of bacterial vaginosis among HIV-positive and HIV-negative pregnant women. Int J Biomedicine 2015;5(3):141-146

23.Taha TE, Hoover DR, Dallabetta GA, et al. Bacterial vaginosis and disturbances of vaginal flora: association with increased acquisition of HIV. AIDS 1998;12:1699-1706

24.Fethers KA, Fairly CK, Hocking JS, Gurrin LC, Bradshaw CS. Sexual risk factors and bacterial vaginosis: A systematic review and meta-analysis. Clinical Infect Dis 2008;47:1426-35 